\title{
Generation of Intensity Selectivity by Differential Synaptic Tuning: Fast-Saturating Excitation But Slow-Saturating Inhibition
}

\author{
Mu Zhou, ${ }^{1,4}$ Huizhong W. Tao, ${ }^{1,3}$ and Li I. Zhang ${ }^{1,2}$ \\ ${ }^{1}$ Zilkha Neurogenetic Institute, ${ }^{2}$ Department of Physiology \& Biophysics, ${ }^{3}$ Department of Cell \& Neurobiology, and ${ }^{4}$ Physiology Graduate Program, Keck \\ School of Medicine, University of Southern California, Los Angeles, California 90033
}

Intensity defines one fundamental aspect of sensory information and is specifically represented in each sensory modality. Interestingly, only in the central auditory system are intensity-selective neurons evolved. These neurons are characterized by nonmonotonic responselevel functions. The synaptic circuitry mechanisms underlying the generation of intensity selectivity from nonselective auditory nerve inputs remain largely unclear. Here, we performed in vivo whole-cell recordings from pyramidal neurons in the rat dorsal cochlear nucleus (DCN), where intensity selectivity first emerges along the auditory neuraxis. Our results revealed that intensity-selective cells received fast-saturating excitation but slow-saturating inhibition with intensity increments, whereas in intensity-nonselective cells excitation and inhibition were similarly slow-saturating. The differential intensity tuning profiles of the monotonic excitation and inhibition qualitatively determined the intensity selectivity of output responses. In addition, the selectivity was further strengthened by significantly lower excitation/inhibition ratios at high-intensity levels compared with intensity-nonselective neurons. Our results demonstrate that intensity selectivity in the DCN is generated by extracting the difference between tuning profiles of nonselective excitatory and inhibitory inputs, which we propose can be achieved through a differential circuit mediated by feedforward inhibition.

\section{Introduction}

In the sensory system of each modality, stimulus intensity must be represented as a fundamental aspect of sensory input. Most sensory neurons have monotonic spike rate versus intensity level functions (i.e., they encode intensity by increasing spike rate as intensity is increased). In the central auditory system, however, another strategy is used by intensity-selective neurons. The spike rate of these neurons initially increases and peaks as sound intensity is increased, and then decreases as sound intensity is further increased, resulting in a nonmonotonic response-level function (Phillips and Kelly, 1989; Phillips et al., 1995). Intensity-selective neurons are observed at every stage of the ascending central auditory pathway (Greenwood and Maruyama, 1965; Brugge et al., 1969; Aitkin and Webster, 1972; Young and Brownell, 1976; Rouiller et al., 1983; Aitkin, 1991; Schreiner et al., 1992; Kuwabara and Suga, 1993; Phillips et al., 1995). In the rat, the number of intensity-selective cortical neurons was found to increase in animals trained to perform an intensity discrimination task,

Received July 31, 2012; revised 0ct. 3, 2012; accepted 0ct. 30, 2012.

Author contributions: H.W.T. and L.I.Z. designed research; M.Z. performed research; M.Z., H.W.T., and L.I.Z. analyzed data; H.W.T. and L.I.Z. wrote the paper.

This work was supported by grants to L.I.Z. from the United States National Institutes of Health/National Institute on Deafness and Other Communication Disorders (R01DC008983), and the David and Lucile Packard Foundation (Packard Fellowships for Science and Engineering). H.W.T was supported by a grant from the United States National Institutes of Health (R01EY019049).

Correspondence should be addressed to L.I. Zhang, Keck School of Medicine, University of Southern California, 1501 San Pablo Street, Los Angeles, CA 90033. E-mail: liizhang@usc.edu.

DOI:10.1523/JNEUROSCI.3647-12.2012

Copyright $\odot 2012$ the authors $\quad 0270-6474 / 12 / 3218068-11 \$ 15.00 / 0$ suggesting that intensity-selective neurons may be required for the precise coding of sound loudness (Polley et al., 2004, 2006).

The neural basis for intensity selectivity remains not well understood. Previous studies have mostly focused on late stages of the auditory neuraxis, in particular the cortex. There, several synaptic mechanisms have been proposed for sharpening intensity selectivity or even generating intensity selectivity de novo (Shamma, 1985; Ojima and Murakami, 2002; Sutter and Loftus, 2003; Wu et al., 2006; Tan et al., 2007; de la Rocha et al., 2008). Intensity selectivity in the cortex may be partially inherited from intensity-selective outputs of previous processing stages, as evidenced by the intensity-tuned excitatory inputs to cortical neurons (Wu et al., 2006; Tan et al., 2007). Along the auditory neuraxis, intensity-selective neurons are first observed in the dorsal cochlear nucleus (DCN) (Young and Brownell, 1976). Because the ascending input to cochlear nuclei is provided by the auditory nerve (AN), which provides nonintensity-tuned responses (Kiang et al., 1965; Sachs and Abbas, 1974), it is interesting to examine DCN neurons to understand how intensity selectivity is initially generated (Fig. 1A). Based on spike response properties of DCN neurons, it has been proposed that the generation of intensity selectivity in the DCN may be attributed to a lower intensity threshold of excitation than inhibition (Voigt and Young, 1980; Nelken and Young, 1994; Davis et al., 1996; Spirou et al., 1999; Young and Davis, 2001). However, because sound-evoked excitatory and inhibitory synaptic inputs to individual DCN neurons have not been experimentally elucidated, this theory remains to be tested.

In the current study, we performed in vivo whole-cell recordings from DCN neurons to directly examine the synaptic mech- 
A

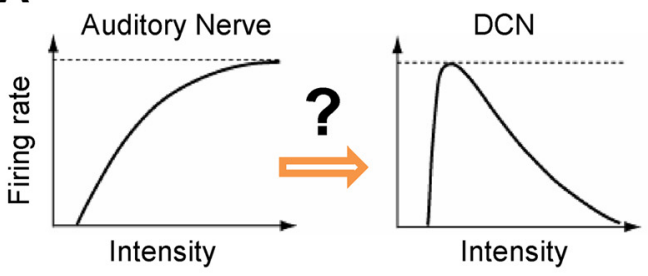

C
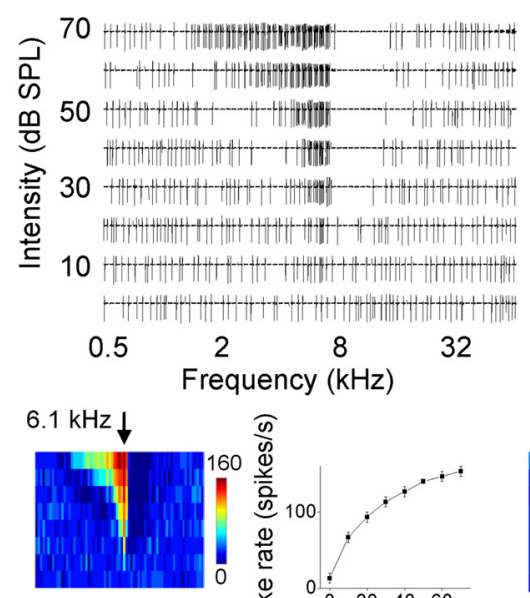

B

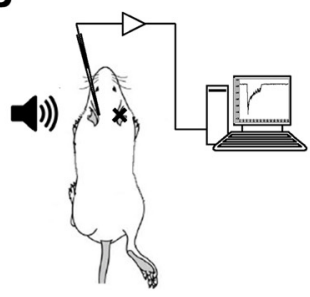

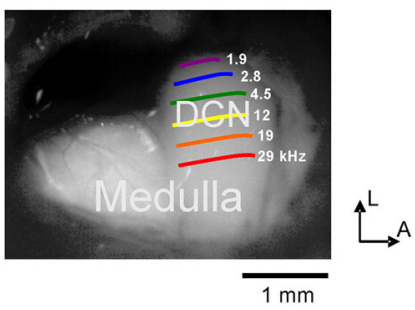

E

Inhibitory
D Intensity-selective
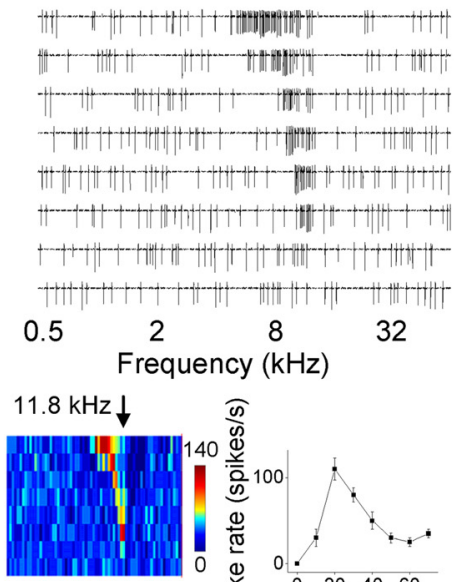

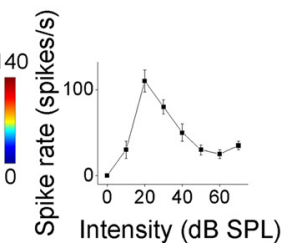

Figure 1. Receptive field properties of rat DCN neurons. $A$, Schematic drawings of intensity tuning function (rate vs intensity level) of the AN as well as of intensity-selective neurons in the DCN. Intensity selectivity is first generated in the DCN, and may be inherited by later processing stages. $\boldsymbol{B}$, Left, Schematic diagram of the experimental setup. Sound is applied to the ear ipsilateral to the recorded DCN. Right, Image of the exposed dorsal surface of the medulla. The tonotopic map in the DCN is indicated by colored lines representing different CFs. The labeling of the frequency axis is based on multiunit recordings in this animal, but is highly reproducible between animals. L, lateral; A, anterior. Scale bar, $1 \mathrm{~mm}$. C, Spike TRF of an intensity-nonselective DCN pyramidal neuron, examined by the cell-attached recording. Top, Each small trace is a record of evoked spikes (1 trial) by a $50 \mathrm{~ms}$ tone of a particular frequency and intensity combination. SPL, sound pressure level. Bottom left, Color map depicts the average spike TRF ( 5 repetitions). Color represents the average spike rate (Hz). CF is marked by the arrow. Bottom right, Plot of spike rate evoked by a CF tone (6.1 $\mathrm{kHz}$ for this cell) versus tone intensity ( $\mathrm{bar}=\mathrm{SE}$ ). Note that the spike rate monotonically increases with increasing intensity. $\boldsymbol{D}$, An example intensity-selective DCN pyramidal neuron. Data are presented in the same way as in $\boldsymbol{C}$. Note that the cell's intensity tuning at $\mathrm{CF}(11.8 \mathrm{kHz})$ is a nonmonotonic function. $\boldsymbol{E}$, An example type II neuron, identified by the sharp TRF, the extremely low level of spontaneous activity, and the absence of responses to broadband noise stimuli (data not shown).

anisms underlying intensity tuning. By isolating the excitatory and inhibitory inputs evoked by the same sound stimuli, we found that the difference in intensity threshold between excitation and inhibition alone is not sufficient for explaining intensity selectivity in the DCN. On the other hand, the differential intensity tuning profiles of excitation and inhibition is key to generating intensity selectivity.

\section{Materials and Methods}

Animal preparation and mapping of the DCN

All experimental procedures used in this study were approved under the Animal Care and Use Committee at the University of Southern California. Experiments were performed in a sound-attenuation booth (Acoustic Systems). Female Sprague Dawley rats ( $\sim 3$ months old and weighing 250-300 g) were anesthetized with ketamine and xylazine (ketamine, 60 $\mathrm{mg} / \mathrm{kg}$; xylazine, $8 \mathrm{mg} / \mathrm{kg}$; i.p.). The body temperature was maintained at $37.5^{\circ} \mathrm{C}$ by a feedback heating system (Harvard Apparatus). The animal was positioned with the left ear facing a calibrated free-field speaker (Vifa), and with a sound-attenuating plug placed in the right ear. After opening the left part of the occipital bone, part of the cerebellum was aspirated to expose the left DCN. Artificial CSF (ACSF; in mM: $124 \mathrm{NaCl}$, $1.2 \mathrm{NaH}_{2} \mathrm{PO}_{4}, 2.5 \mathrm{KCl}, 25 \mathrm{NaHCO}_{3}, 20$ Glucose, $2 \mathrm{CaCl}_{2}, 1 \mathrm{MgCl}_{2}$ ) was applied when necessary during the surgery and the experiment to clean the DCN surface. To map the tonotopy, multiunit spike responses were recorded with a parylene-coated tungsten microelectrode ( $2 \mathrm{M} \Omega, \mathrm{FHC})$ at $100-300 \mu \mathrm{m}$ below the DCN surface. Signals were amplified, bandpass filtered between 0.3 and $10 \mathrm{kHz}$ (Plexon), and then thresholded to extract the timing of each spike using custom-made software (LabView, National Instrument). To obtain tonal receptive fields, pure tones (0.5-64 $\mathrm{kHz}$ at 0.1 octave intervals, $50 \mathrm{~ms}$ duration, $3 \mathrm{~ms}$ ramp) at eight $10 \mathrm{~dB}$ spaced sound intensities (sound pressure level, $0-70 \mathrm{~dB}$ ) were delivered in a pseudorandom sequence. The time interval and intensity difference between two sequential tones were set at $0.5-1 \mathrm{~s}$ and $\leq 30 \mathrm{~dB}$, respectively, as to minimize cross-interactions between the two stimuli. Characteristic frequency (CF), the frequency at which neurons reliably responded to tones with the minimum intensity, was determined for each recording site. As illustrated in Figure $1 B$, a clear low-frequency-tohigh-frequency gradient along the lateral-medial axis can be observed in the rat DCN, similar as described previously (Yajima and Hayashi, 1989; Kaltenbach and Lazor, 1991).

In vivo whole-cell and loose-patch recordings

Whole-cell recordings (Wu et al., 2008; Sun et al., 2010; Zhou et al., 2010, 2012) were made with an Axopatch 200B amplifier (Molecular Devices). Patch pipettes made from borosilicate glass capillaries (Kimax) had an impedance of 3-4 M $\Omega$. Pipettes contained a potassium-based solution composed of (in mM) the following: $130 \mathrm{~K}$-gluconate, $4 \mathrm{MgATP}, 0.3$ GTP, 8 phosphocreatine, $10 \mathrm{HEPES}, 11 \mathrm{EGTA}, 5 \mathrm{KCl}, 1 \mathrm{CaCl}_{2}, 0.2$ fluorescein dextran, $\mathrm{pH}$ 7.3. The patch pipette was lowered into the DCN at an angle of $\sim 85^{\circ}$. The brainstem was then covered with $3.5 \%$ agar prepared in warm ACSF. Whole-cell capacitance was fully compensated and the initial series resistance $(<30 \mathrm{M} \Omega)$ was compensated for $40-60 \%$. Signals were filtered at $5 \mathrm{kHz}$ and sampled at $10 \mathrm{kHz}$. Only cells with 
A

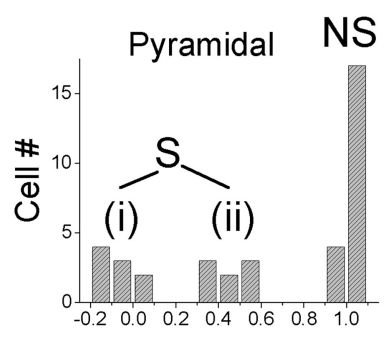

Intensity selectivity index

E

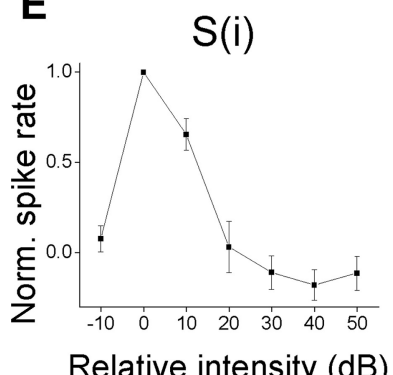

B

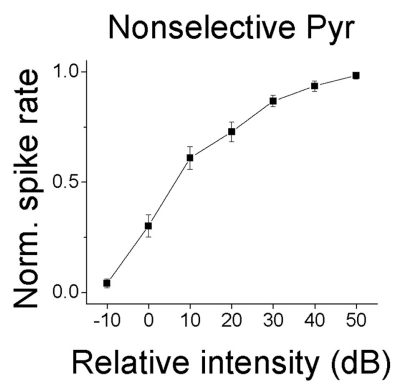

F

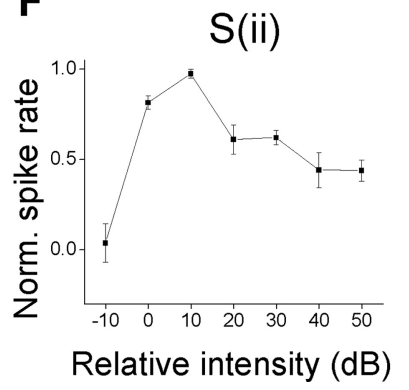

C

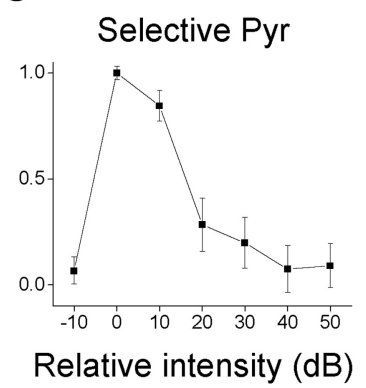

D

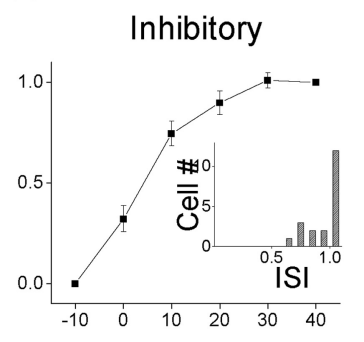

Relative intensity $(\mathrm{dB})$
G

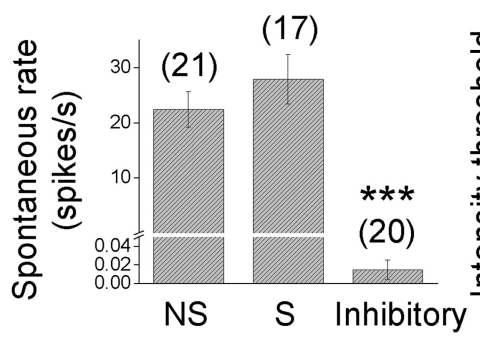

H

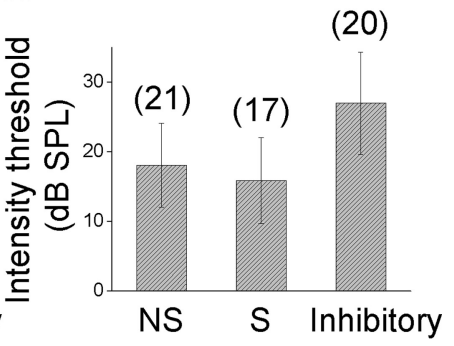

Figure 2. Summary of intensity tuning properties of several types of DCN neurons. $A$, Distribution of intensity selectivity indices of pyramidal cells. Note that only a subset of nonselective cells $(I S I=1)$ are shown in this graph. $\boldsymbol{B}$, Average intensity tuning profile for nonselective (NS) pyramidal cells (bar $=S E ; n=21)$. C, Average tuning profile for selective (S) pyramidal cells $(n=17)$. $\boldsymbol{D}$, Average tuning profile for inhibitory type II neurons. Inset, Distribution of ISIs for type II neurons $(n=20)$. $\boldsymbol{E}$, Average tuning profile for the "Si" group of intensity-selective pyramidal cells $(n=$ 9). $\boldsymbol{F}$, Average tuning profile for the "Sii" group of intensity-selective pyramidal cells $(n=8) . \boldsymbol{G}$, Average spontaneous firing rate for different types of cells. NS, intensity-nonselective pyramidal; $S$, intensity-selective pyramidal (bar $=\mathrm{SE}$ ). ${ }^{*} p<0.001$, ANOVA with post hoc test. $\boldsymbol{H}$, Average intensity threshold for different types of cells (bar $=\mathrm{SE}$ ). ${ }^{*} p<0.05$, ANOVA with post hoc test.

resting membrane potential lower than $-50 \mathrm{mV}$ were studied. A $10 \mathrm{mV}$ junction potential was corrected. Excitatory and inhibitory currents were recorded by clamping the cell at -70 and $0 \mathrm{mV}$ respectively. The morphology of some recorded cells was reconstructed by confocal fluorescence imaging of the cells filled with fluorescein dextran $(0.2 \mathrm{mM}$, Invitrogen) in fixed brainstem sections.

In this study, we specifically focused on fusiform cells in the pyramidal cell layer. We controlled our recording depths according to the travel distance of the pipette tip. Because there is no pial tissue covering the DCN and pipette penetrations caused little dimpling of the DCN surface, there was relatively precise correspondence between travel distance and recording depth. Also, for consistent control of recording depth, we chose to record from the middle frequency representation region because the DCN surface in this region is parallel to the horizontal plane. Our reported pyramidal neurons were recorded at $100-250 \mu \mathrm{m}$ depths below the surface, corresponding to the pyramidal cell layer (Mugnaini et al., 1980; Wouterlood and Mugnaini, 1984). Due to the depth control, giant cells, another type of DCN projection neurons, were presumably rarely encountered. The pyramidal cell type was confirmed by completely constructed dendritic morphologies in four cells (Fig. 2A; Hancock and Voigt, 2002), and the somata location in the pyramidal cell layer was also confirmed by six partially recovered cells (data not shown). In addition, the response properties of the recorded pyramidal cells were consistent with those previously reported (Evans and Nelson, 1973; Young and Brownell, 1976).

For loose-patch recordings, pipettes were filled with ACSF. Loose seal (100-200 M $\Omega$ ) was made from neurons, allowing spikes only from the patched cell to be recorded. Recording was under the voltage-clamp mode. A command voltage was applied to achieve a zero baseline current. Signals were filtered at $0.3-10 \mathrm{kHz}$ and sampled at $20 \mathrm{kHz}$. For recordings from inhibitory neurons, pipettes of smaller tip openings (impedance, $\sim 10 \mathrm{M} \Omega$ ) were used to overcome a bias toward larger cells (Wu et al., 2008). We specifically searched for a type of inhibitory neurons, type II cells, at 250-700 $\mu \mathrm{m}$ depths (Mugnaini et al., 1980; Rhode, 1999) using tone and noise stimuli. We identified type II cells by their lack of spontaneous activity and absence of responses to broadband noise stimuli at $60 \mathrm{~dB}$ sound pressure level. Cells with complex spikes, potentially cart- wheel cells (Portfors and Roberts, 2007), were excluded from the analysis in this study.

\section{Data analysis}

Tone-evoked responses. Spikes recorded in the loose-patch configuration could be detected without ambiguity because their amplitudes were normally $>100 \mathrm{pA}$, while the baseline fluctuation was $<5 \mathrm{pA}$. Tone-driven spikes were counted within a $4-60 \mathrm{~ms}$ time window after the tone onset. The average spontaneous spike number within the same time duration was subtracted from the number of evoked spikes. Intensity threshold was defined at the tip of the tonal receptive field (TRF) by the minimal intensity level at which CF tones reliably evoked responses. The evoked response should be higher than the average baseline activity by 3 SDs of the baseline fluctuation. All the synaptic response traces evoked by the same test stimulus were averaged. The peak amplitude of the average trace was determined by averaging pixels within a $\pm 5 \mathrm{~ms}$ time window centered on the maximum value. The integrated conductance was calculated by deriving the synaptic conductance and then integrating conductance within 4-60 ms after the tone onset.

Synaptic conductances. Excitatory synaptic conductance and inhibitory synaptic conductance were derived (Borg-Graham et al., 1998; Anderson et al., 2000; Zhang et al., 2003; Wu et al., 2008; Sun et al., 2010) according to $\Delta I=G_{\mathrm{e}}\left(V-E_{\mathrm{e}}\right)+G_{\mathrm{i}}\left(V-E_{\mathrm{i}}\right) \cdot \Delta I$ is the amplitude of the synaptic current response at any time point after subtraction of the baseline current; $G_{\mathrm{e}}$ is the excitatory synaptic conductance; $G_{\mathrm{i}}$ is the inhibitory synaptic conductance; $V$ is the holding voltage; and $E_{\mathrm{e}}(0 \mathrm{mV})$ and $E_{\mathrm{i}}(-70$ $\mathrm{mV}$ ) are the reversal potentials. The clamping voltage $V$ was corrected from the applied holding voltage $\left(V_{\mathrm{h}}\right): V=V_{\mathrm{h}}-R_{\mathrm{s}}{ }^{\star} I$, where $R_{\mathrm{s}}$ is the effective series resistance. By holding the recorded cell at two different voltages (the reversal potentials for excitatory and inhibitory currents respectively), $G_{\mathrm{e}}$ and $G_{\mathrm{i}}$ were resolved from the equation.

Derived membrane potential responses. The membrane potential change caused by synaptic conductances could be derived according to an integrate-and-fire neuron model (Somers et al., 1995; Liu et al., 2007; Zhang et al., 2011a): $V_{\mathrm{m}}(t+d t)=-(d t / C)\left[G_{\mathrm{e}}(t) *\left(V_{\mathrm{m}}(t)-E_{\mathrm{e}}\right)+G_{\mathrm{i}}(t)\right.$ $\left.*\left(V_{\mathrm{m}}(t)-E_{\mathrm{i}}\right)+G_{\mathrm{r}}\left(V_{\mathrm{m}}(t)-E_{\mathrm{r}}\right)\right]+V_{\mathrm{m}}(t)$, where $V_{\mathrm{m}}(t)$ is the membrane potential at time $t, C$ is the whole-cell capacitance, $G_{\mathrm{r}}$ is the resting leaky 
conductance, and $E_{\mathrm{r}}$ is the resting membrane potential $(-60 \mathrm{mV})$. To simulate the spike response, $20 \mathrm{mV}$ above the resting membrane potential was set as the spike threshold and a $5 \mathrm{~ms}$ refractory period was used. $C(20-50 \mathrm{pF})$ was measured during the experiment and $G_{\mathrm{r}}$ was calculated based on the equation $G_{\mathrm{r}}=C^{\star} G_{\mathrm{m}} / C_{\mathrm{m}}$, where $G_{\mathrm{m}}$, the specific membrane conductance, is $2 e-5 \mathrm{~S} / \mathrm{cm}^{2}$, and $C_{\mathrm{m}}$, the specific membrane capacitance, is $1 e-6 \mathrm{~F} / \mathrm{cm}^{2}$ (Hines, 1993; Stuart and Spruston, 1998).

\section{Results}

\section{Intensity tuning functions of rat DCN neurons}

It was previously proposed in the cat and gerbil DCN that intensity-selective neurons have lower intensity thresholds of spike response than inhibitory neurons in DCN, and that this difference in intensity threshold can explain the generation of the selectivity (Voigt and Young, 1980; Nelken and Young, 1994; Spirou et al., 1999; Young and Davis, 2001; Oertel and Young, 2004). We examined this proposed mechanism in the rat by first characterizing intensity tuning functions of its DCN neurons. After exposing the dorsal surface of the cochlear nucleus in the brainstem, in vivo cell-attached loose-patch recordings were made from individual neurons in the DCN to obtain their spike responses evoked by tones of different frequencies and intensities (see Materials and Methods). In this study, we specifically focused on fusiform/pyramidal cells, the DCN projection neurons located in layer 2 (Mugnaini et al., 1980; Wouterlood and Mugnaini, 1984; see Materials and Methods). The frequency-intensity TRF was reconstructed from recorded spikes, and the CF was determined at the intensity threshold of the spike TRF (see Materials and Methods). The response-level function (i.e., intensity tuning) of the cell was then tested by applying CF tones at different intensities for a number of repetitions. Two types of pyramidal neurons were observed. Examples are given in Figure 1C,D. For the first type, neurons exhibited typical V-shaped spike TRFs, and inhibitory side bands were apparent when the spontaneous firing rate was relatively high (Fig. $1 C$, top and color map). They exhibited monotonic response-level functions, as indicated by a continuous increase in response level as the intensity of CF tones increased (Fig. 1C, lower right). These neurons can thus be viewed as intensity-nonselective, and are functionally similar to previously reported type III or type I/III cells (Evans and Nelson, 1973; Young and Voigt, 1982; Davis et al., 1996). In this work, we did not further separate them into type III (with inhibitory sidebands) and type I/III (without apparent inhibitory sidebands) neurons. For the second type, the response-level function for CF tones was nonmonotonic: the spike rate first reached a peak and then declined at higher intensity levels (Fig. 1D). These neurons can be viewed as intensity-selective, and are functionally consistent with previously reported type IV neurons (Evans and Nelson, 1973; Young and Voigt, 1982; Davis et al., 1996). Their TRFs were not typical $\mathrm{V}$-shaped, since the responses at or near CF at high intensity levels were reduced.

We used an intensity selectivity index (ISI) to quantify the selectivity level. It was defined as the ratio of the response at $30 \mathrm{~dB}$ above the preferred intensity or at the highest testing intensity over the maximum response. A perfect monotonic response-level function would generate an ISI of 1 . As shown by the distribution of ISIs, pyramidal cells appeared to cluster into three groups (Fig. $2 A$ ). The first group ("NS") had ISIs of 1 or close to 1 , and the average response-level function for this group was clearly monotonic (Fig. 2B). According to the ISI distribution and the previous criterion for defining intensity-selective neurons (Ding and Voigt, 1997; Wu et al., 2006), we defined intensity-selective neurons in this study as having an ISI of $<0.6$. The second and third group (Fig. 2A, "Si" and "Sii") were therefore collectively intensity-selective neurons, with their average response-level function exhibiting a stronger nonmonotonicity (Fig. 2C). The "Si" group, however, exhibited much strong intensity selectivity than the "Sii" group. In the "Si" group, CF tones at high intensities could completely suppress spiking activity, resulting in a negative response relative to the baseline activity (Fig. $2 E$ ). In the "Sii" group, on the other hand, spike rate at the highest testing intensity was only reduced to $\sim 40 \%$ of the maximum (Fig. $2 F$ ). These two groups, one strongly selective and the other moderately selective, may correspond to previously reported "type IV" and "type IV-t" neurons respectively (Evans and Nelson, 1973; Davis et al., 1996). Within the pyramidal cell population, only $13 \%$ (17 of 129) of cells were intensity selective. This relatively small percentage of intensity-selective neurons was also reported in other rodents (Davis et al., 1996; Navawongse and Voigt, 2009; Ma and Brenowitz, 2012).

Previously, type II neurons have been thought to play an important role in creating intensity selectivity. They have been demonstrated to be vertical cells in morphology and be inhibitory in function (Davis and Voigt, 1997; Rhode, 1999). We specifically searched type II cells in the deep layer (see Materials and Methods). They could be identified by little or no spontaneous firing activity, absence of response to broadband noise stimuli, and strong response to CF tones (Evans and Nelson, 1973; Young and Voigt, 1982; Young and Davis, 2001). An example type II neuron is shown in Figure 1E. The cell exhibited almost zero spontaneous activity, a narrow V-shaped TRF, and monotonic intensitytuning function. A summary of response-level function for 20 type II neurons is shown in Figure $2 D$. All type II neurons were intensity-nonselective with ISIs $>0.6$ (Fig. $2 D$, inset). Compared with pyramidal cells (both intensity nonselective and selective), which have $20-30 \mathrm{~Hz}$ spontaneous spike rates, the extremely low spontaneous rate of type II neurons made them easily distinguished (Fig. 2G). The type II neurons had significantly higher intensity thresholds than both the intensity-nonselective and intensity-selective pyramidal cells (Fig. $2 \mathrm{H}$ ), consistent with previous reports in cats and gerbils. The two types of pyramidal cells did not differ in intensity threshold (Fig. $2 H$ ). This result suggests that in both types of pyramidal neurons the intensity threshold of inhibition may be higher than that of excitation. Therefore, the generation of intensity selectivity may not be simply attributed to a difference in intensity threshold between excitation and inhibition.

\section{Excitatory and inhibitory synaptic inputs to DCN neurons}

To reveal the synaptic basis for intensity selectivity, we performed whole-cell current-clamp and voltage-clamp recordings from the same DCN neuron (see Materials and Methods). First, in the current-clamp recording mode, the spike TRF was obtained to determine the cell's CF and whether the cell was intensityselective. CF tone-evoked excitatory and inhibitory synaptic responses at different intensities were then recorded under the voltage-clamp mode. An example intensity-nonselective cell is shown in Figure $3 A-C$. The mapping of spike TRF revealed that the cell's CF was at $15.3 \mathrm{kHz}$ (Fig. $3 A$ ). At this frequency, changes of spike response with increasing intensity indicated that the cell was monotonic (Fig. 3B, Sp). The subsequent voltage-clamp recording revealed that at the intensity threshold of spike response (marked as " $0 \mathrm{~dB}$ "), there was significant tone-evoked excitatory input, but not inhibitory input (Fig. 3B, Ex and In, respectively). From the plotting of peak amplitude of evoked synaptic currents (Fig. $3 C$ ), it is clear that both the excitatory and inhibitory inputs 
A

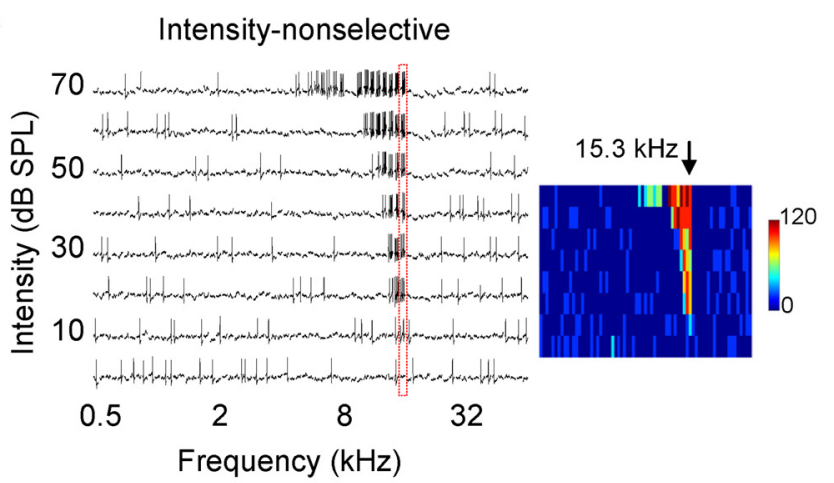

B

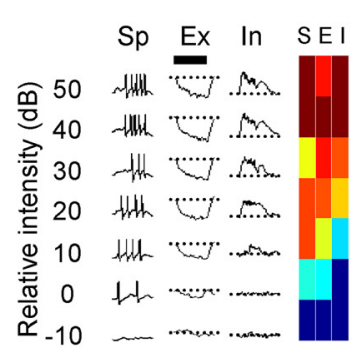

G
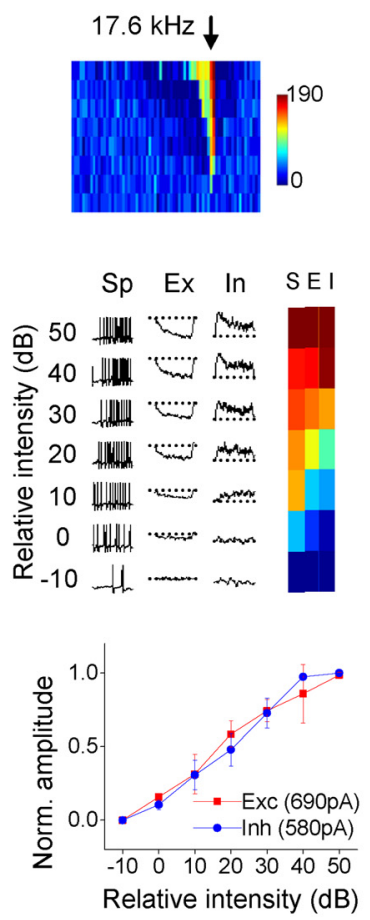

$\mathbf{K}$

NS

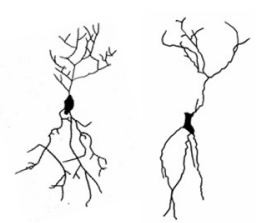

C

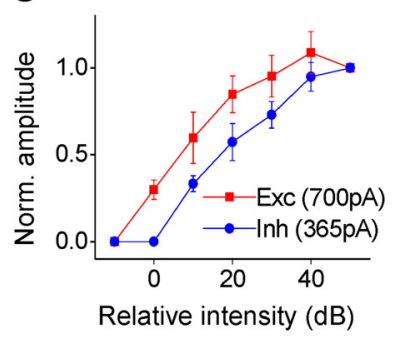

H
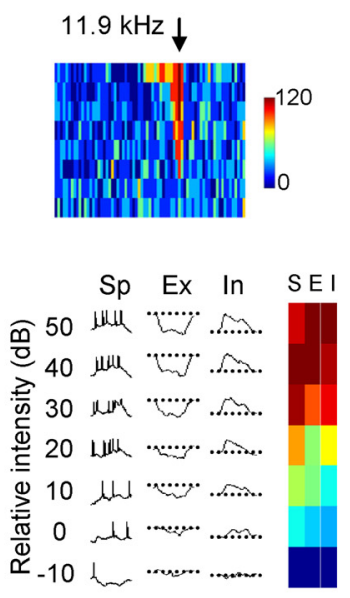

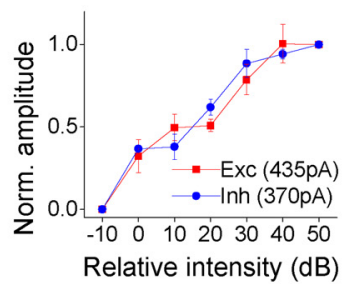

S

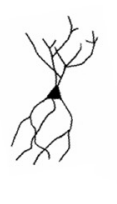

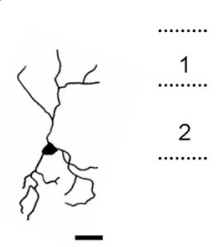

D

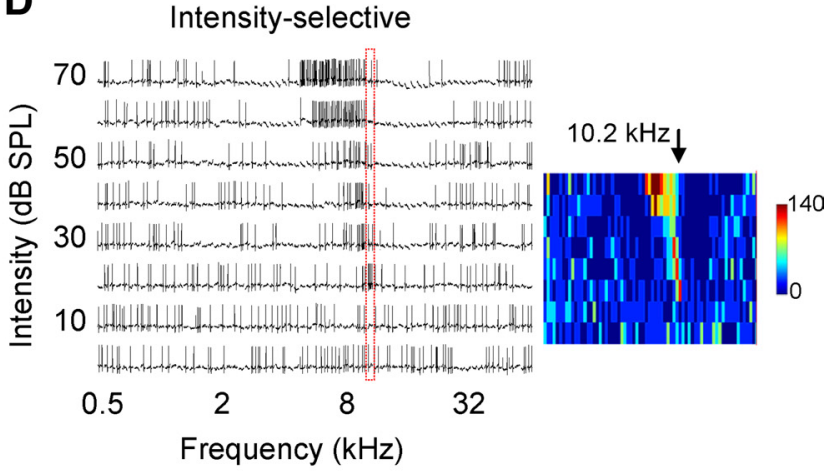

E

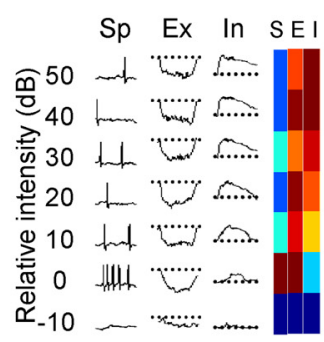

F

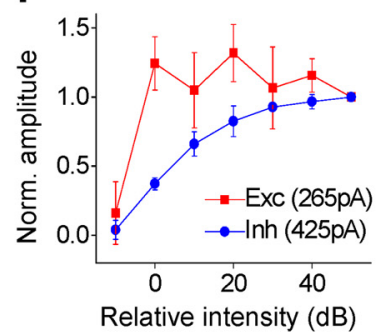

I $\quad 10.3 \mathrm{kHz} \downarrow$

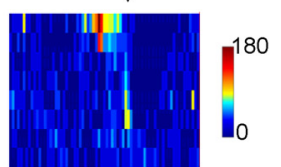

J

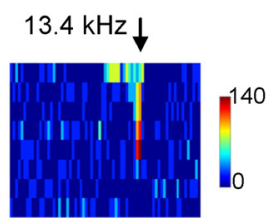

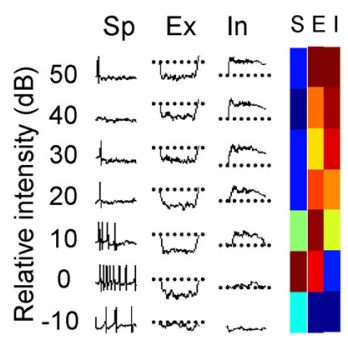
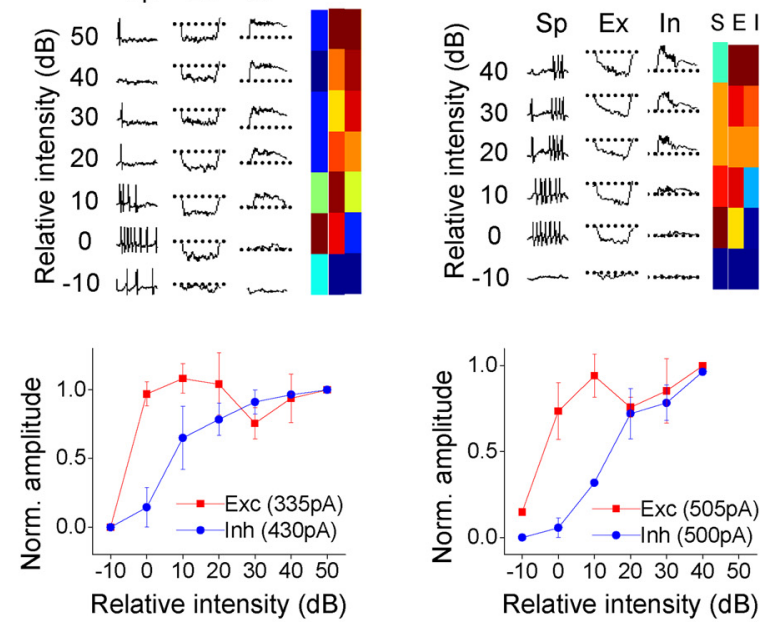

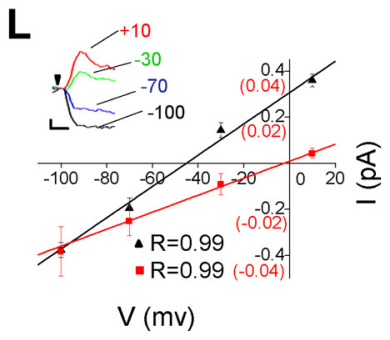

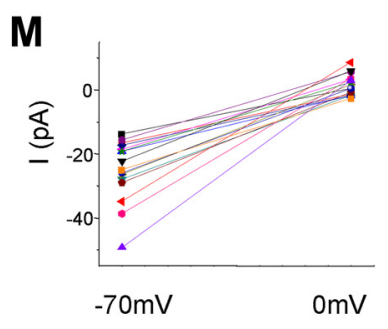

Figure 3. Synaptic inputs to example DCN pyramidal neurons. $A$, Spike TRF of an example intensity-nonselective pyramidal neuron, examined by the whole-cell current-clamp recording. The dotted box outlines the responses to $\mathrm{CF}(15.3 \mathrm{kHz})$ tones. Right, Color map depicts the average spike TRF. Color represents the average spike rate. $\boldsymbol{B}$, Records of CF tone-evoked spikes, average traces (4 repetitions) of (F tone-evoked excitatory (Exc) and inhibitory (Inh) responses at different intensities for the same cell as in $A$. The intensity threshold of spike response is denoted as $0 \mathrm{~dB}$. The short line on top of the trace indicates the duration of the tone stimulation ( $50 \mathrm{~ms}$ ). Color bar on the right represents the magnitude of responses. Maximum value for the color scale is $100 \mathrm{~Hz}, 700 \mathrm{pA}$, and $365 \mathrm{pA}$, respectively. Baseline is indicated by the dotted line. C, Plot of normalized peak amplitude of excitation and inhibition versus tone intensity. The maximum amplitude (Figure legend continues.) 
were gradually strengthened as intensity increased, and that the intensity threshold of the inhibitory input was higher than the excitatory input. An example intensity-selective cell is shown in Figure $3 D-F$. In this cell, the amplitudes of excitatory and inhibitory inputs also increased with intensity increments, indicating that synaptic inputs per se are not intensity-selective. However, different from the intensity-nonselective neuron, its excitatory input appeared to quickly reach a plateau level as soon as the intensity threshold for spike response was reached (Fig. 3F).

More example intensity-nonselective and intensity-selective neurons are shown in Figure $3 G, H$ and Figure $3 I$, J, respectively. For the intensity-nonselective neurons, excitatory and inhibitory inputs increased with similar paces. In contrast, for the intensityselective neurons whose spike responses decreased at high intensities, the excitatory response increased faster than the inhibitory response with increasing intensity.

The whole-cell recording allowed labeling of the recorded cells with dyes. Complete dendritic morphologies were reconstructed for two intensity-nonselective and two intensity-selective neurons (Fig. $3 \mathrm{~K}$ ). The cells were all pyramidal cells located in layer 2 (i.e., pyramidal cell layer), as evidenced by the presence of apical and basal dendrites as well as the spindle-like cell body shape (Young and Davis, 2001). Six partially recovered cells were also located in the pyramidal cell layer and were identified as fusiform cells based on the soma shape (data not shown). There was no apparent difference in morphology between intensitynonselective and intensity-selective pyramidal neurons (Fig. $3 K$ ). We also estimated the quality of our voltage-clamp recordings by plotting the current-voltage $(I-V)$ relationship for the recorded synaptic currents. As shown by an example cell (Fig. $3 L$ ), synaptic currents evoked by CF tones were recorded under four different membrane potentials. The current amplitude at $1 \mathrm{~ms}$ after the response onset (Fig. $3 L$, red) changed linearly with voltage, with the reversal potential matching that expected for excitatory currents $(0 \mathrm{mV})$. The current amplitude at $11 \mathrm{~ms}$ after the onset (Fig. $3 L$, black) also changed linearly with voltage, but the reversal potential was $-46 \mathrm{mV}$, indicating a combination of excitatory and inhibitory currents at this time point. We next examined CF tone-evoked synaptic currents at $1 \mathrm{~ms}$ after the response onset in all the recorded pyramidal cells (Fig. $3 M$ ). The currents were all close to zero when the membrane was clamped at the excitatory reversal potential. The linear $I-V$ relationship as well as the relatively precise excitatory reversal potential as revealed suggest that voltage-clamp quality was reasonably good in our experiments.

\section{Synaptic tuning profiles and inhibition/excitation ratio}

We summarized synaptic tuning profiles from nine intensitynonselective and five intensity-selective pyramidal neurons. As

\footnotetext{
(Figure legend continued.) is given (bar $=S D) . \boldsymbol{D}-\boldsymbol{F}$, An example intensity-selective pyramidal neuron. Data are displayed in a similar manner. Maximum value for the color scale in $E$ is 120 $\mathrm{Hz}, 265 \mathrm{pA}$, and $425 \mathrm{pA}$, respectively. $\boldsymbol{G}, \boldsymbol{H}$, Two more example intensity-nonselective cells. Maximum value for the color scale is (from left to right) as follows: $\boldsymbol{G}, 150 \mathrm{~Hz}, 690 \mathrm{pA}, 580 \mathrm{pA} ; \boldsymbol{H}$, $120 \mathrm{~Hz}, 435 \mathrm{pA}, 370 \mathrm{pA} . I, J$, Two more example intensity-selective cells. Maximum value for the color scale is as follows: $I, 160 \mathrm{~Hz}, 335 \mathrm{pA}, 430 \mathrm{pA} ; J, 140 \mathrm{~Hz}, 505 \mathrm{pA}, 500 \mathrm{pA}$. $\boldsymbol{K}$, Reconstructed morphology for two intensity-nonselective and two intensity-selective cells. DCN layers are labeled. Note that the cell bodies were all located in layer 2. Scale bar, $50 \mu \mathrm{m} . L, I-V$ curve for recorded synaptic currents in an example cell. Red, Average current amplitude within a $1 \mathrm{~ms}$ window $1 \mathrm{~ms}$ after the synaptic response onset. Black, Average current amplitude within a $1 \mathrm{~ms}$ window $11 \mathrm{~ms}$ after the onset. $R$, correlation coefficient. Note that the $y$-axis scale is different for the red and black plot. Inset, Response traces at different voltages (mV). Scale bars, $100 \mathrm{pA}, 10$ ms. $M$, Amplitudes of CF tone-evoked synaptic currents at two voltages in all the recorded cells. Amplitudes were measured within a $1 \mathrm{~ms}$ window at $1 \mathrm{~ms}$ after the synaptic response onset.
}

shown in Figure $4 A, B$ by the normalized peak response amplitude, intensity-nonselective and intensity-selective neurons differed dramatically in the relationship between excitatory and inhibitory intensity tuning profiles. Excitation and inhibition were similarly increasing with intensity increments in nonselective neurons, while in selective neurons excitation saturated much faster than inhibition. The same conclusion can be made when the integrated conductance was measured (Fig. 4C,D, see Materials and Methods). Between intensity-selective and intensity-nonselective cells, there was no difference in inhibitory tuning profile, while their excitatory tuning profiles significantly differed in terms of slope (Fig. $4 E, F$ ). Consistent with the loosepatch recording results, excitation had a lower intensity threshold than inhibition in both intensity-selective and intensitynonselective neurons (Fig. 4G). This intensity threshold difference between excitation and inhibition was not different between the two types of pyramidal cells ( $p>0.1, t$ test).

In addition to intensity tuning profile, the relative and absolute strengths of excitatory or inhibitory inputs may also contribute to intensity selectivity. We further compared the amplitudes of excitatory and inhibitory inputs between the two types of pyramidal neurons. As shown in Figure $5 A$, at the intensity threshold, excitation was stronger in selective than in nonselective neurons. However, at $50 \mathrm{~dB}$ above the intensity threshold, excitation in selective neurons became weaker than in nonselective neurons, due to its early saturation with intensity increments. On the other hand, the absolute level of inhibition was not significantly different between the two types of pyramidal neurons at either intensity (Fig. $5 A$ ). Figure $5 B$ plots the change of inhibition/excitation (I/E) ratio with intensity increments. The I/E ratio was more or less constant above the intensity threshold in nonselective neurons, whereas it kept increasing in selective neurons. At the highest testing intensity, the selective neurons received relatively stronger inhibition compared with the nonselective neurons (Fig. 5B). As for the temporal properties of synaptic responses, we found that the onset delay of inhibition relative to excitation reduced with intensity increments for both intensity-selective and intensity-nonselective neurons (Fig. 5C). This shortening of relative delay of inhibition can be accounted for at least partially by the intensity-dependent changes of the excitatory response onset and the spike response onset of inhibitory type II neurons (Fig. 5D).

\section{Neuronal modeling of the generation of intensity selectivity}

We have shown that intensity-selective and intensitynonselective neurons differ in excitatory tuning profile and absolute excitatory strength. Intuitively, the differential intensity tuning profile of excitation may fully account for the functional difference between intensity-selective and intensity-nonselective neurons. In the intensity-selective neuron, excitation is close to saturation at the intensity threshold (it reaches $>80 \%$ of the peak level), whereas at this intensity level inhibition is nearly the lowest (Fig. 4A,B). This may lead to a strong output response at the intensity threshold. With intensity further increasing, inhibition catches up, and the level of spike response may gradually fall.

To demonstrate how much the observed excitatory and inhibitory tuning profiles can account for the intensity tuning profile of output responses in a quantitative manner, we used a conductance-based single-compartment integrate-and-fire neuron model (Liu et al., 2007; Zhou et al., 2012). Feeding it with experimentally obtained excitatory and inhibitory synaptic conductances, we derived the expected membrane potential and spike responses at different tone intensities on a cell-by-cell basis (see Materials and Methods). As shown in Figure $5 E, F$, the in- 
tensity tuning profile of derived spike responses could largely match that of recorded responses for both intensitynonselective and intensity-selective neurons. This suggests that the interplay of somatically recorded excitatory and inhibitory responses can qualitatively determine the tuning property of the cell. Next, to test whether the differential intensity tuning profiles of excitatory input play a critical role in determining intensity-selective or intensity-nonselective properties, we exchanged the excitatory tuning profiles between the intensity-selective and intensity-nonselective groups. This was achieved in each individual cell by keeping the excitatory response at the highest intensity fixed while scaling the response amplitudes at other intensities according to the average excitatory tuning profile for the other neuronal type (Fig. $5 G, H$, top). The scaled excitatory response was then integrated with the original inhibitory response to derive spike response. Through this one-step swapping procedure, the tuning of intensity-nonselective neurons became slightly nonmonotonic (Fig. $5 G$, magenta), while that of intensityselective neurons was changed to monotonic (Fig. $5 H$, magenta).

We noticed that the swapping of excitatory tuning profiles only produced modestly nonmonotonic spike responses. This apparent deviation from recorded intensity-selective responses may be due to a difference in absolute strength of synaptic inputs between the two types of pyramidal neurons (Fig. 5A). For example, in nonselective neurons, the excitatory response at the highest testing intensity is strong and may result in nearly saturated spike response, leaving little room for the input at lower intensities to generate even stronger spike response. In the following procedure, in addition to swapping the excitatory tuning profile, we also scaled the excitatory response amplitudes in general so that the $\mathrm{I} / \mathrm{E}$ ratio at the highest intensity was the same as that observed for the other neuronal type. In other words, we swapped the I/E ratios of the two types of cells. As shown in Figure 5G,H (cyan), the two-step swapping procedure converted the intensity-nonselective responses to more in vivo-like intensity-selective responses, while the intensity-selective responses were completely switched to monotonic responses. These modeling results demonstrate that the differential tuning relationship between excitation and inhibition plus the differential excitatory input strength can explain the functional difference between intensity-selective and intensity-nonselective neurons. Thus, these two factors may play key roles in generating intensity selectivity in the DCN.
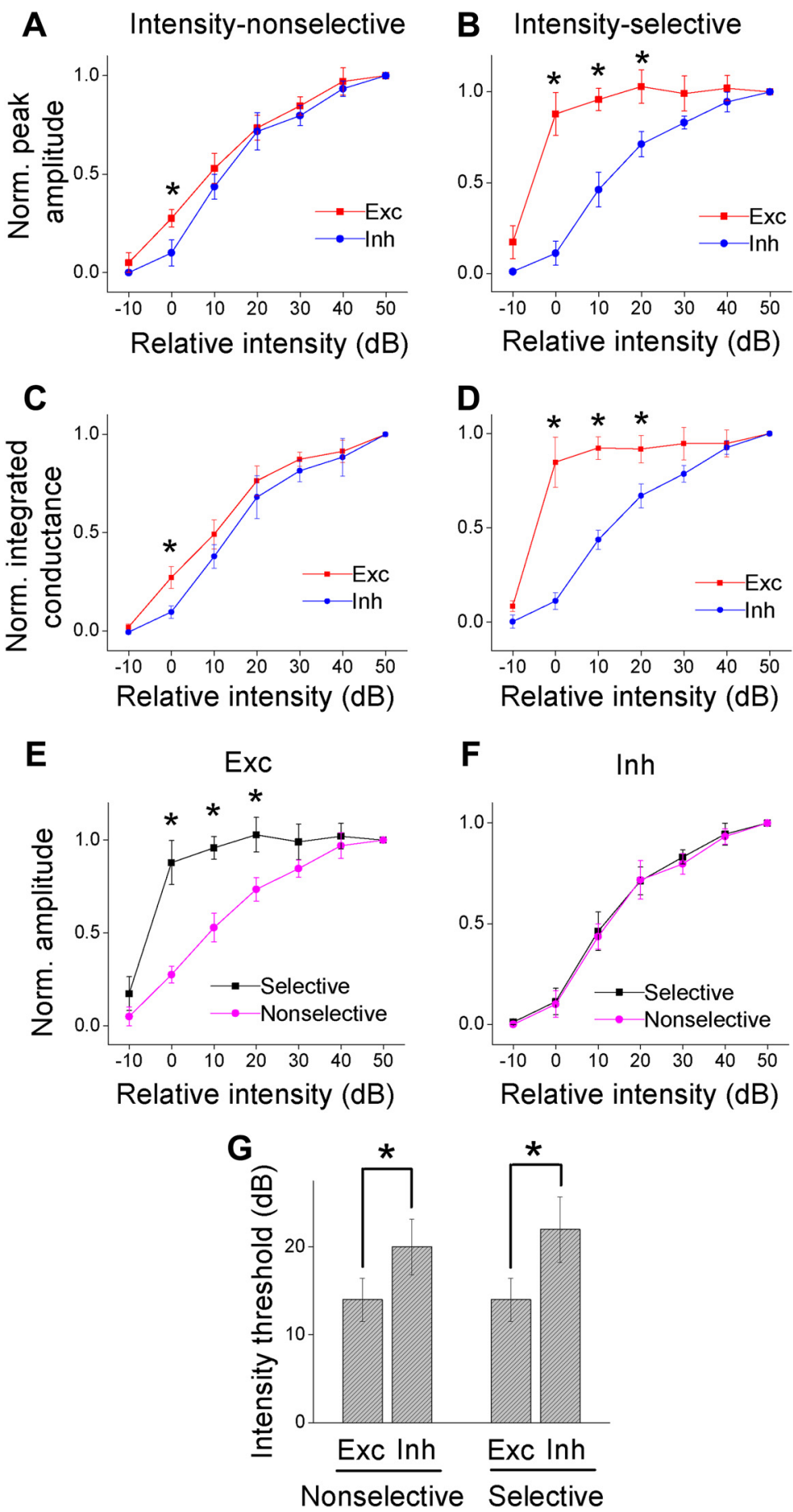

Figure 4. Summary of properties of excitation and inhibition underlying intensity tuning functions of DCN pyramidal neurons. $\boldsymbol{A}, \boldsymbol{B}$, Average normalized intensity tuning functions of intensity-nonselective $(n=9)$ and intensity-selective $(n=5)$ neurons. The peak response amplitude was measured (bar $=S E$ ). ${ }^{*} p<0.05$, paired $t$ test. $C, D$, Average normalized intensity tuning functions based on the integrated conductance (bar $=\mathrm{SE}$ ). ${ }^{*} p<0.05$, paired $t$ test. $\boldsymbol{E}, \boldsymbol{F}$, Comparison of excitatory and inhibitory tuning profiles between intensity-nonselective and intensity-selective neurons based on peak amplitudes (bar $=\mathrm{SE}$ ). ${ }^{*} p<0.05, t$ test. $\mathbf{G}$, Average intensity threshold of excitation and inhibition for the two types of neurons (bar $=\mathrm{SE}$ ). ${ }^{*} p<0.05$, paired $t$ test.

\section{Discussion}

In this study, we applied in vivo whole-cell recordings to examine synaptic mechanisms underlying the creation of intensity selectivity in the DCN. To our knowledge, this is the first time excitatory and inhibitory synaptic inputs underlying functional selectivity at this earliest stage of central auditory processing are elucidated. Our results confirmed that synaptic inputs to DCN 
A

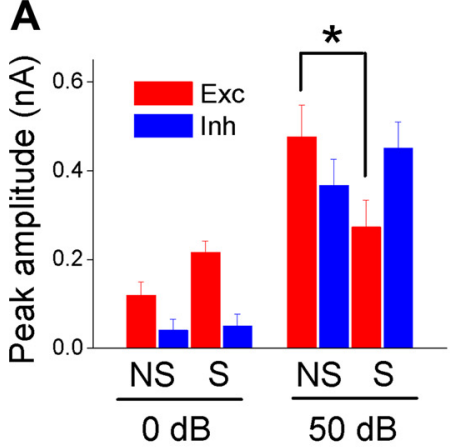

B

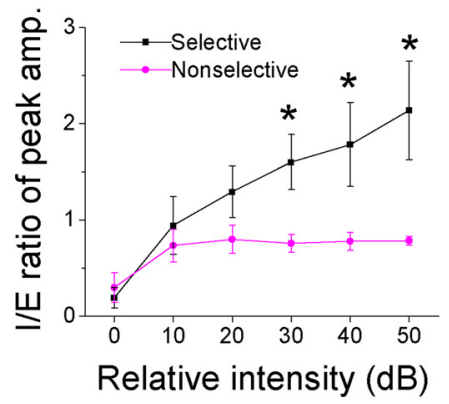

C

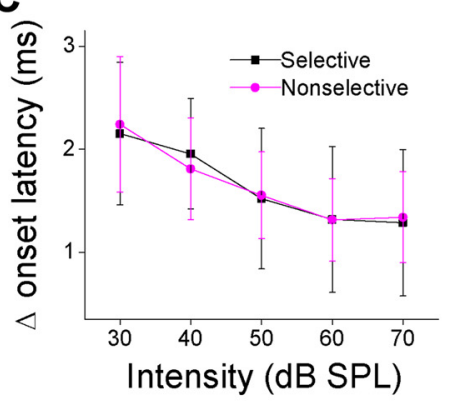

$\mathbf{E}$

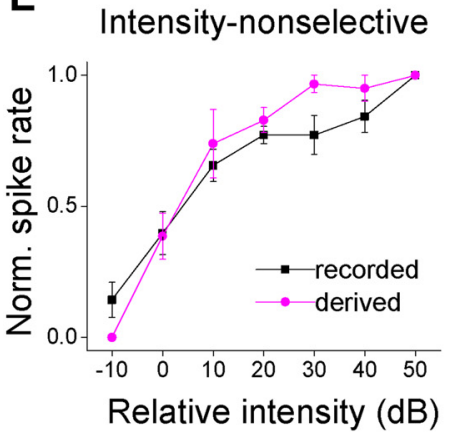

G

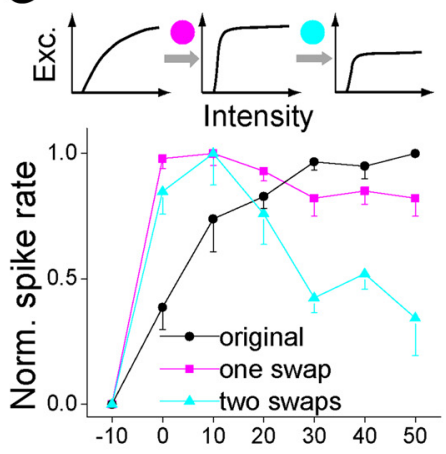

Relative intensity $(\mathrm{dB})$

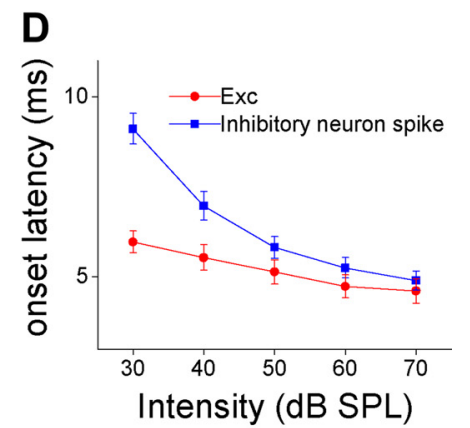

$\mathbf{F}$
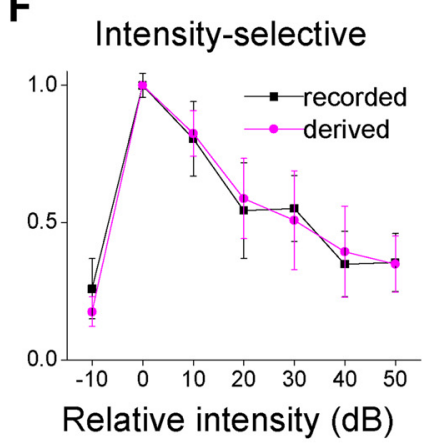

H
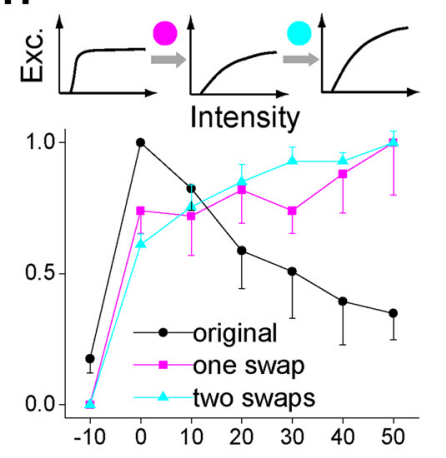

Relative intensity $(\mathrm{dB})$

Figure 5. Synaptic mechanisms underlying the generation of intensity selectivity. $\boldsymbol{A}$, Average peak amplitudes of excitation and inhibition in intensity-nonselective (NS, $n=9$ ) and intensity-selective $(S, n=5)$ pyramidal neurons evoked by CF tones at 0 and $50 \mathrm{~dB}$ (relative). ${ }^{*} p<0.05, t$ test. $\boldsymbol{B}$, Average $\mathrm{I} /$ Eratio plotted as a function of relative intensity for nonselective and selective neurons (bar $=\mathrm{SE}$ ). ${ }^{*} p<0.05$, $t$ test. $C$, The difference between onset latencies of excitatory and inhibitory responses plotted against tone intensity (error bars are SE). $\boldsymbol{D}$, The onset latency of excitation for all the recorded pyramidal neurons $(n=14)$ and that of spiking response of inhibitory neurons $(n=20)$ (error bars are SE). $\boldsymbol{E}, \boldsymbol{F}$, Average intensity tuning profiles of spike responses recorded experimentally and those derived by integrating the experimentally obtained excitatory and inhibitory responses in the neuron model for nonselective $(n=9)$ and selective ( $n=5$ ) neurons (error bars are SE). $\mathbf{G}, \boldsymbol{H}$, Average intensity tuning profiles of spike responses derived by integrating experimentally recorded excitatory and inhibitory responses (black), and by integrating the recorded inhibitory responses and scaled excitatory responses (magenta, cyan). Top panel depicts how swapping procedures were carried out. One swap: the scaling of excitatory responses was according to the average excitatory tuning profile of the other neuronal type, with the response at the highest intensity fixed. Two swaps: excitatory responses were further scaled (without changing the intensity tuning profile) to achieve an I/E ratio at the highest intensity the same as that observed for the other neuronal type (error bars are SE).

neurons all exhibit monotonic intensity tuning functions. Two synaptic mechanisms contribute to the converting of monotonic inputs to nonmonotonic outputs. First, the differential intensity tuning profiles of excitation and inhibition (i.e., fast-saturating excitation but slowsaturating inhibition) are a fundamental basis for the generation of intensity selectivity. Second, the lower level of excitation or relatively stronger inhibition at high intensities further strengthens the intensity selectivity of output responses.

\section{Intensity selectivity in central auditory system}

Nonmonotonic intensity-tuned neurons have been widely observed along the ascending pathway of the central auditory system [e.g., in the cochlear nucleus (Greenwood and Maruyama, 1965; Young and Brownell, 1976, Ramachandran et al., 1999), inferior colliculus (Aitkin, 1991; Kuwabara and Suga, 1993), medial geniculate body (Aitkin and Webster, 1972; Rouiller et al., 1983), and auditory cortex (Davies et al., 1956; Evans and Whitfield, 1964; Brugge et al., 1969; Schreiner et al., 1992; Phillips et al., 1995; Wu et al., 2006; Tan et al., 2007; Sadagopan and Wang, 2008)]. It has been thought that the selectivity can be generated de novo at later stages of the auditory pathway. For example, in earlier studies of the auditory cortex, it has been postulated that an intensity-dependent increase of inhibition can result in nonmonotonic response-level functions (Ojima and $\mathrm{Mu}$ rakami, 2002; Sutter and Loftus, 2003). These studies were based on extracellular recordings of spike responses under twotone stimuli or intracellular recordings of tone-evoked membrane potential responses, both of which detect inhibition in an indirect way. More recent whole-cell recording studies have revealed that excitatory inputs to intensity-selective auditory cortical neurons are already well tuned, indicating that intensity selectivity in the cortex can be partially inherited from previous stages, although local cortical inhibition can further sharpen the selectivity (Wu et al., 2006; Tan et al., 2007; Zhang et al., 2011b). Thus, it is worthwhile to examine the first stage where the selectivity is initially generated.

The receptive field maps of intensityselective pyramidal cells in this study look different from the circumscribed, O-shaped response maps often observed in the cortex (e.g., Phillips and Kelly, 1989; Wu et al., 2006, Sadagopan and Wang, 2008), which have perfect intensity selectivity. The DCN 
A1

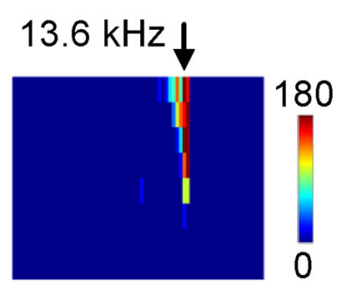

A2

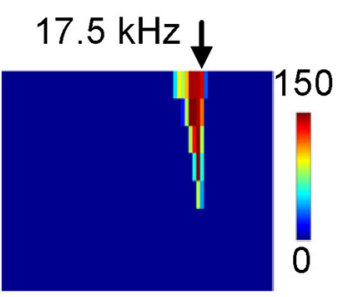

Sp Ex SE
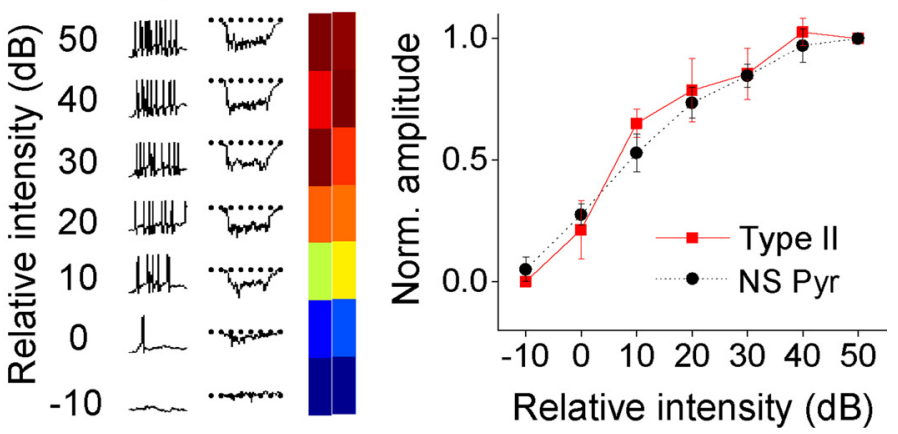

\section{Sp Ex SE}
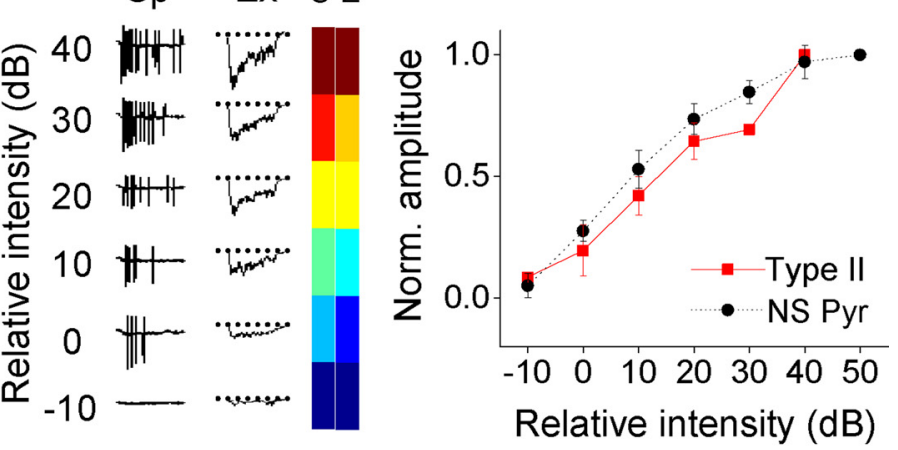

B

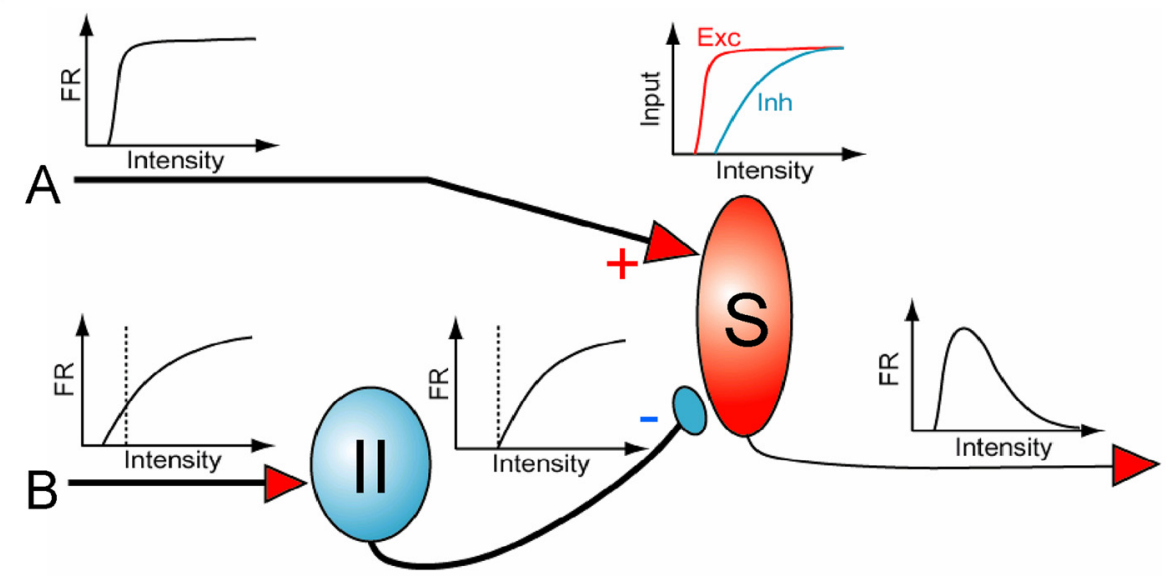

Figure 6. A proposed model for the generation of intensity selectivity in the DCN. A1, A2, Two example type II neurons. The spike and excitatory responses evoked by $C F$ tones at different intensities are displayed in a similar manner as in Figure 2. Middle, Maximum value for the color scale is $180 \mathrm{~Hz}, 285 \mathrm{pA}$ in $\boldsymbol{A 1}$, and $150 \mathrm{~Hz}, 510 \mathrm{pA}$ in $\boldsymbol{A 2}$. Right, Black marks the average excitatory intensity tuning curve for intensity-nonselective pyramidal neurons. $\boldsymbol{B}$, In our proposed model, the intensity-selective pyramidal neuron receives excitatory input from afferent that shows fast-saturating firing rate (FR) with intensity increments (Input A). Another type of afferent that shows slow-saturating FR (Input B) innervates inhibitory type II neurons, the output of which thresholds and reverses the sign (-) of their afferent input. Due to the spike thresholding effect on inhibitory neuron responses, the threshold of inhibition to the pyramidal neuron becomes elevated compared with the excitation. Through this differential circuit, the pyramidal neuron is able to detect the difference between the intensity tuning patterns of the two types of afferent, as reflected by the differential tuning patterns of excitation and inhibition, and to report this difference as the intensity-selective output.

receptive field maps are not completely enclosed, and intensity tuning functions at off-CF can be in fact monotonic. Possibly, along the ascending auditory pathway, recruitments of inhibition (e.g., lateral inhibition) at each higher processing stage progressively sculpt the receptive field map, in particular by silencing CF and off-CF responses at high intensity levels (Sutter and Loftus, 2003; Sadagopan and Wang, 2008; de la Rocha et al., 2008; Wu etal., 2011; Zhang etal., 2011b). This may eventuallylead to the emergence of $\mathrm{O}$-shaped receptive field maps in the cortex.

\section{Synaptic mechanisms underlying intensity selectivity}

To convert monotonic response-level functions to nonmonotonic functions, synaptic inhibition is generally thought to be required (Shamma, 1985; Phillips, 1988; Calford and Semple, 1995; Ding and Voigt, 1997). Previously, three different scenarios have been postulated with regard to how the excitatory-inhibitory interplay might generate intensity tuning. First, based on the observation that inhibitory type II neurons exhibit a higher intensity threshold than their principal neuron counterparts (Voigt and Young, 1980; Spirou et al., 1999), it is suggested that a lower intensity threshold of excitation than inhibition may result in the highest E/I ratio and the strongest spike response at the excitatory intensity threshold (Nelken and Young, 1994; Young and Davis, 2001). Our data however indicate that in both intensity-selective and intensity-nonselective neurons, the intensity threshold of ex- 
citation is $\sim 10 \mathrm{~dB}$ lower than that of inhibition. Therefore, a threshold difference alone does not necessarily produce intensity tuning. Second, it has been found for intensity-selective cortical neurons that the onset latency of inhibition relative to excitation shortens with intensity increments (Wu et al., 2006). Modeling work further suggests that this intensity-dependent decrease in the temporal delay of inhibition can sufficiently produce intensity-tuned output responses (Wu et al., 2006). In the DCN, we found that the relative delay of inhibition was only slightly reduced with intensity increments and that it was not different between intensity-selective and intensity-nonselective neurons (Fig. 5C). In addition, because DCN responses are much more sustained than cortical responses (Wehr and Zador, 2003; Zhang et al., 2003; Tan et al., 2004), any small variations of relative inhibitory delay would not affect the overall response level significantly. Third, a theoretic study of thalamocortical networks has demonstrated that under certain network properties unbalanced recruitments of excitation and inhibition can occur such that inhibition grows slower than excitation with intensity increments (de la Rocha et al., 2008). Under such unbalanced excitation and inhibition, the integrated output response peaks well before inhibition reaches maximum. Consistent with this postulate, unbalanced recruitments of excitation and inhibition occur in the DCN and play a key role in generating intensity selectivity.

\section{Potential underlying circuits}

How can the unbalanced recruitments of excitation and inhibition be achieved? Previously, a circuit with broad lateral inhibition was proposed for cortical neurons to result in a slower recruitment of inhibition than excitation as the number of inhibitory neurons activated gradually increases with increasing intensity (Sutter and Loftus, 2003; de la Rocha et al., 2008). This mechanism requires that the receptive fields of inhibitory neurons be relatively broad and be spectrally offset but have overlapping regions. Here in the DCN, we notice that the speed of recruitment of inhibition does not differ between intensityselective and intensity-nonselective neurons (Fig. $4 F$ ). It appears that it is the recruitment pattern of excitation that makes the difference.

The two different excitatory tuning patterns observed in intensity-nonselective and intensity-selective neurons were reminiscent of the two types of intensity-dependent responses of auditory nerve fibers reported previously: fast saturating and slow saturating (Sachs and Abbas, 1974; Winter et al., 1990). This raises an interesting possibility that the different excitatory tuning patterns may be conveyed from the two different types of auditory nerve inputs, as it has been well documented that pyramidal neurons receive direct auditory nerve inputs (Oertel and Young, 2004). In addition, we found in two intracellularly recorded type II neurons that they received slowly saturating excitatory input similar to intensity-nonselective pyramidal neurons (Fig. 6A). This observation suggests that the slow-saturating inhibition to pyramidal neurons could be relayed by inhibitory type II neurons innervated by slow-saturating auditory nerve fibers. Based on the above evidence, we propose a simple model that can explain DCN intensity selectivity (Fig. 6B). In this model, the intensity tuning properties of excitation and inhibition are simply inherited from auditory nerve fibers. The intensity-selective pyramidal neuron may receive fast-saturating excitatory input from fast-saturating auditory nerve fibers (Input A), and slowsaturating inhibitory input from inhibitory neurons driven by slow-saturating auditory nerve input (Input B). Through such a feedforward inhibitory circuit likely mediated by type II/vertical cells (Voigt and Young, 1980; Oertel and Young, 2004; Kuo et al., 2012), the threshold of inhibition becomes higher than excitation due to the spike thresholding effect on inhibitory neuron responses, while the intensity tuning function of inhibition remains slow-saturating. In addition, the low spontaneous activity of type II neurons (Fig. 2G) may also contribute to their higher intensity threshold, since relatively stronger auditory nerve input is required to drive these cells compared with pyramidal neurons. By this analogous differential circuit, the pyramidal neuron can extract the difference between the intensity tuning patterns of Input $A$ and Input B to create intensity-selective output responses. The overall structure of our proposed circuit is in line with the one previously proposed for type IV neurons (Voigt and Young, 1980; Spirou et al., 1999), except that differential AN fiber inputs are incorporated. It is unknown why AN fibers have different saturation slopes. Is it due to distinct properties of different types of spiral ganglion cells? How specific is the connectivity between different types of DCN neurons and different types of AN fibers? The proposed synaptic circuitry mechanism for the generation of intensity selectivity raises many interesting questions for future investigations.

\section{References}

Aitkin L (1991) Rate-level functions of neurons in the inferior colliculus of cats measured with the use of free-field sound stimuli. J Neurophysiol 65:383-392. Medline

Aitkin LM, Webster WR (1972) Medial geniculate body of the cat: organization and responses to tonal stimuli of neurons in ventral division. J Neurophysiol 35:365-380. Medline

Anderson JS, Carandini M, Ferster D (2000) Orientation tuning of input conductance, excitation, and inhibition in cat primary visual cortex. J Neurophysiol 84:909-926. Medline

Borg-Graham LJ, Monier C, Frégnac Y (1998) Visual input evokes transient and strong shunting inhibition in visual cortical neurons. Nature 393: 369-373. CrossRef Medline

Brugge JF, Dubrovsky NA, Aitkin LM, Anderson DJ (1969) Sensitivity of single neurons in auditory cortex of cat to binaural tonal stimulation; effects of varying interaural time and intensity. J Neurophysiol 32:10051024. Medline

Calford MB, Semple MN (1995) Monaural inhibition in cat auditory cortex. J Neurophysiol 73:1876-1891. Medline

Davies PW, Erulkar SD, Rose JE (1956) Single unit activity in the auditory cortex of the cat. Bull Johns Hopkins Hosp 99:55-86. Medline

Davis KA, Voigt HF (1997) Evidence of stimulus-dependent correlated activity in the dorsal cochlear nucleus of decerebrate gerbils. J Neurophysiol 78:229-247. Medline

Davis KA, Ding J, Benson TE, Voigt HF (1996) Response properties of units in the dorsal cochlear nucleus of unanesthetized decerebrate gerbil. J Neurophysiol 75:1411-1431. Medline

de la Rocha J, Marchetti C, Schiff M, Reyes AD (2008) Linking the response properties of cells in auditory cortex with network architecture: Cotuning versus lateral inhibition. J Neurosci 28:9151-9163. CrossRef Medline

Ding J, Voigt HF (1997) Intracellular response properties of units in the dorsal cochlear nucleus of unanesthetized decerebrate gerbil. J Neurophysiol 77:2549-2572. Medline

Evans EF, Nelson PG (1973) The responses of single neurones in the cochlear nucleus of the cat as a function of their location and the anaesthetic state. Exp Brain Res 17:402-427. Medline

Evans EF, Whitfield IC (1964) Classification of unit responses in the auditory cortex of the unanaesthetized and unrestrained cat. J Physio 171: 476-493. Medline

Greenwood DD, Maruyama N (1965) Excitatory and inhibitory response areas of auditory neurons in the cochlear nucleus. J Neurophysiol 28:863892. Medline

Hancock KE, Voigt HF (2002) Intracellularly labeled fusiform cells in dorsal cochlear nucleus of the gerbil. I. Physiological response properties. J Neurophysiol 87:2505-2519. Medline

Hines M (1993) NEURON-a program for simulation of nerve equations. 
In: Neural systems: analysis and modeling. (F. Eeckman, ed). Norwell, MA: Kluwer Academic.

Kaltenbach JA, Lazor J (1991) Tonotopic maps obtained from the surface of the dorsal cochlear nucleus of the hamster and rat. Hear Res 51:149-160. CrossRef Medline

Kiang NY, Watanabe T, Thomas EC, Clark LF (1965) Discharge patterns of single fibers in the cat's auditory nerve. Cambridge, MA: MIT.

Kuo SP, Lu HW, Trussell LO (2012) Intrinsic and synaptic properties of vertical cells of the mouse dorsal cochlear nucleus. J Neurophysiol 108: 1186-1198. CrossRef Medline

Kuwabara N, Suga N (1993) Delay lines and amplitude selectivity are created in subthalamic auditory nuclei: the brachium of the inferior colliculus of the mustached bat. J Neurophysiol 69:1713-1724. Medline

Liu BH, Wu GK, Arbuckle R, Tao HW, Zhang LI (2007) Defining cortical frequency tuning with recurrent excitatory circuitry. Nat Neurosci 10: 1594-1600. CrossRef Medline

Ma WL, Brenowitz SD (2012) Single-neuron recordings from unanesthetized mouse dorsal cochlear nucleus. J Neurophysiol 107:824-835. CrossRef Medline

Mugnaini E, Warr WB, Osen KK (1980) Distribution and light microscopic features of granule cells in the cochlear nuclei of cat, rat, and mouse. J Com Neurol 191:581-606. CrossRef

Navawongse R, Voigt HF (2009) Single neuron recordings in dorsal cochlear nucleus (DCN) of awake gerbil. Hear Res 255:44-57. CrossRef Medline

Nelken I, Young ED (1994) Two separate inhibitory mechanisms shape the responses of dorsal cochlear nucleus type IV units to narrowband and wideband stimuli. J Neurophysiol 71:2446-2462. Medline

Oertel D, Young ED (2004) What's a cerebellar circuit doing in the auditory system? Trends Neurosci 27:104-110. CrossRef Medline

Ojima H, Murakami K (2002) Intracellular characterization of suppressive responses in supragranular pyramidal neurons of cat primary auditory cortex in vivo. Cereb Cortex 12:1079-1091. CrossRef Medline

Phillips DP (1988) Effect of tone-pulse rise time on rate-level functions of cat auditory cortex neurons: excitatory and inhibitory processes shaping responses to tone onset. J Neurophysiol 59:1524-1539. Medline

Phillips DP, Kelly JB (1989) Coding of tone-pulse amplitude by single neurons in auditory cortex of albino rats (Rattus norvegicus). Hear Res 37: 269-279. CrossRef Medline

Phillips DP, Semple MN, Kitzes LM (1995) Factors shaping the tone level sensitivity of single neurons in posterior field of cat auditory-cortex. J Neurophysiol 73:674-686. Medline

Polley DB, Heiser MA, Blake DT, Schreiner CE, Merzenich MM (2004) Associative learning shapes the neural code for stimulus magnitude in primary auditory cortex. Proc Natl Acad Sci U S A 101:16351-16356. CrossRef Medline

Polley DB, Steinberg EE, Merzenich MM (2006) Perceptual learning directs auditory cortical map reorganization through top-down influences. J Neurosci 26:4970-4982. CrossRef Medline

Portfors CV, Roberts PD (2007) Temporal and frequency characteristics of cartwheel cells in the dorsal cochlear nucleus of the awake mouse. J Neurophysiol 98:744-756. CrossRef Medline

Ramachandran R, Davis KA, May BJ (1999) Single-unit responses in the inferior colliculus of decerebrate cats. I. Classification based on frequency response maps. J Neurophysiol 82:152-163. Medline

Rhode WS (1999) Vertical cell responses to sound in cat dorsal cochlear nucleus. J Neurophysiol 82:1019-1032. Medline

Rouiller E, de Ribaupierre Y, Morel A, de Ribaupierre F (1983) Intensity functions of single unit responses to tone in the medial geniculate body of cat. Hear Res 11:235-247. CrossRef Medline

Sachs MB, Abbas PJ (1974) Rate versus level functions for auditory-nerve fibers in cats: tone-burst stimuli. J Acoust Soc Am 56:1835-1847. CrossRef Medline

Sadagopan S, Wang X (2008) Level invariant representation of sounds by populations of neurons in primary auditory cortex. J Neurosci 28:34153426. CrossRef Medline

Schreiner CE, Mendelson JR, Sutter ML (1992) Functional topography of cat primary auditory cortex: representation of tone intensity. Exp Brain Res 92:105-122. Medline

Shamma SA (1985) Speech processing in the auditory system. II: lateral in- hibition and the central processing of speech evoked activity in the auditory nerve. J Acoust Soc Am 78:1622-1632. CrossRef Medline

Somers DC, Nelson SB, Sur M (1995) An emergent model of orientation selectivity in cat visual cortical simple cells. J Neurosci 15:5448-5465. Medline

Spirou GA, Davis KA, Nelken I, Young ED (1999) Spectral integration by type II interneurons in dorsal cochlear nucleus. J Neurophysiol 82:648 663. Medline

Stuart G, Spruston N (1998) Determinants of voltage attenuation in neocortical pyramidal neuron dendrites. J Neurosci 18:3501-3510. Medline

Sun YJ, Wu GK, Liu BH, Li P, Zhou M, Xiao Z, Tao HW, Zhang LI (2010) Fine-tuning of pre-balanced excitation and inhibition during auditory cortical development. Nature 465:927-931. CrossRef Medline

Sutter ML, Loftus WC (2003) Excitatory and inhibitory intensity tuning in auditory cortex: evidence for multiple inhibitory mechanisms. J Neurophysiol 90:2629-2647. CrossRef Medline

Tan AY, Atencio CA, Polley DB, Merzenich MM, Schreiner CE (2007) Unbalanced synaptic inhibition can create intensity-tuned auditory cortex neurons. Neuroscience 146:449-462. CrossRef Medline

Tan AY, Zhang LI, Merzenich MM, Schreiner CE (2004) Tone-evoked excitatory and inhibitory synaptic conductances of primary auditory cortex neurons. J Neurophysiol 92:630-643. CrossRef Medline

Voigt HF, Young ED (1980) Evidence of inhibitory interactions between neurons in dorsal cochlear nucleus. J Neurophysiol 44:76-96. Medline

Wehr M, Zador AM (2003) Balanced inhibition underlies tuning and sharpens spike timing in auditory cortex. Nature 426:442-446. CrossRef Medline

Winter IM, Robertson D, Yates GK (1990) Diversity of characteristic frequency rate-intensity functions in guinea-pig auditory-nerve fibers. Hear Res 45:191-202. CrossRef Medline

Wouterlood FG, Mugnaini E (1984) Cartwheel neurons of the dorsal cochlear nucleus-a Golgi-electron microscopic study in rat. J Com Neurol 227:136-157. CrossRef

Wu GK, Li P, Tao HW, Zhang LI (2006) Nonmonotonic synaptic excitation and imbalanced inhibition underlying cortical intensity tuning. Neuron 52:705-715. CrossRef Medline

Wu GK, Arbuckle R, Liu BH, Tao HW, Zhang LI (2008) Lateral sharpening of cortical frequency tuning by approximately balanced inhibition. Neuron 58:132-143. CrossRef Medline

Wu GK, Tao HW, Zhang LI (2011) From elementary synaptic circuits to information processing in primary auditory cortex. Neurosci Biobehav Rev 35:2094-2104. CrossRef Medline

Yajima Y, Hayashi Y (1989) Response properties and tonotopical organization in the dorsal cochlear nucleus in rats. Exp Brain Res 75:381-389. Medline

Young ED, Brownell WE (1976) Responses to tones and noise of single cells in dorsal cochlear nucleus of unanesthetized cats. J Neurophysiol 39:282300. Medline

Young ED, Davis KA (2001) Circuitry and function of the DCN. New York: Springer.

Young ED, Voigt HF (1982) Response properties of type II and type III units in dorsal cochlear nucleus. Hear Res 6:153-169. CrossRef Medline

Zhang LI, Tan AY, Schreiner CE, Merzenich MM (2003) Topography and synaptic shaping of direction selectivity in primary auditory cortex. Nature 424:201-205. CrossRef Medline

Zhang M, Liu Y, Wang SZ, Zhong W, Liu BH, Tao HW (2011a) Functional elimination of excitatory feedforward inputs underlies developmental refinement of visual receptive fields in zebrafish. J Neurosci 31:5460-5469. CrossRef Medline

Zhang LI, Zhou Y, Tao HW (2011b) Perspectives on: information and coding in mammalian sensory physiology: inhibitory synaptic mechanisms underlying functional diversity in auditory cortex. J Gen Physiol 138:311320. CrossRef Medline

Zhou Y, Liu BH, Wu GK, Kim YJ, Xiao Z, Tao HW, Zhang LI (2010) Preceding inhibition silences layer 6 neurons in auditory cortex. Neuron 65:706-717. CrossRef Medline

Zhou Y, Mesik L, Sun YJ, Liang F, Xiao Z, Tao HW, Zhang LI (2012) Generation of spike latency tuning by thalamocortical circuits in auditory cortex. J Neurosci 32:9969-9980. CrossRef Medline 